\section{Review: the STRATIFY prediction tool has limited accuracy for predicting falls in hospital and geriatric rehabilitation inpatients}

\section{QUESTION}

How well does the STRATIFY tool predict falls in hospital and geriatric rehabilitation inpatients?

\section{REVIEW SCOPE}

Included studies evaluated the STRATIFY tool (score range 05) for predicting falls in hospital inpatients exclusively, and reported sufficient data to calculate the outcomes of interest, including number of falls or patients who fell, sensitivity, and specificity.

\section{REVIEW METHODS}

Medline, CINAHL, EMBASE/Excerpta Medica, AARP Ageline, Cochrane Database of Systematic Reviews, ACP Journal Club, DARE, and Controlled Clinical Trials Register (all 1997 to Feb 2006), and reference lists were searched for prospective studies that included original data and were published in peerreviewed journals or letters to the editor. Studies that used the STRATIFY tool with a cut-off score $\geqslant 2$ exclusively in a geriatric rehabilitation population to predict patients who fell were included in the meta-analysis. 8 studies met the selection criteria: 4 ( $n=1285$, mean age range 67-81 y, mean follow-up 10-50 d) were done in geriatric rehabilitation settings, and 4
( $n=2599$, mean age range 78-84 y, mean follow-up $15 \mathrm{~d}$ to 2 mo) were done in acute medical or mixed medical/rehabilitation settings.

\section{MAIN RESULTS}

Pooled data from 4 studies done in geriatric rehabilitation settings showed that STRATIFY scores $\geqslant 2$ had a sensitivity of $67 \%$ and specificity of $51 \%$ for predicting patients who fell (table). Data from 4 studies done in acute or mixed settings were not pooled. In these studies, cut-off scores for predicting falls and predictive ability of the STRATIFY tool varied (sensitivity range 19-93\%, specificity 49-88\%, \{positive likelihood ratio [LR] 1.6 to 7.8 , and negative LR 0.08 to 0.92$\}^{*}$ ).

\section{CONCLUSION}

The STRATIFY tool has limited accuracy for predicting falls in hospital and geriatric rehabilitation inpatients.

${ }^{*}$ Calculated from data in article.

\section{ABSTRACTED FROM}

Oliver D, Papaioannou A, Giangregorio L, et al. A systematic review and meta-analysis of studies using the STRATIFY tool for prediction of falls in hospital patients: how well does it work? Age Ageing 2008;37:621-7.

Correspondence to: Dr D Oliver, City University, London, UK

Source of funding: no external funding.

Clinical impact ratings: Elderly care 5/7; General/internal medicine 5/7; Rehabilitation 5/7

Pooled data for STRATIFY scores $\geqslant 2$ for predicting patients who fell in geriatric rehabilitation settings at a mean follow-up of $10-50$ days*

\begin{tabular}{llllll}
\hline $\begin{array}{l}\text { Number of } \\
\text { trials }(\mathbf{n})\end{array}$ & $\begin{array}{l}\text { Patients } \\
\text { who fell }\end{array}$ & Sensitivity (95\% CI) & Specificity (CI) & Positive likelihood ratio & Negative likelihood ratio \\
\hline $4(1285)$ & $18 \%$ & $67(61$ to 74$)$ & $51(43$ to 59$)$ & 1.4 & 0.64 \\
\hline
\end{tabular}

*Likelihood ratios calculated from data in article.

$\mathrm{D}$ ata show that patient falls increase healthcare costs, length of hospital stay, and subsequent morbidity and mortality. ${ }^{1}$ As a result, the Joint Commission now requires that a method be in place to screen patients at risk of falls, ${ }^{2}$ and the Centers for Medicare and Medicaid include fall prevalence and fall reporting as part of their reportable quality measures. ${ }^{3}$

Several tools currently exist for fall risk identification, such as Morse, Hendrich II, and STRATIFY. ${ }^{4}$ The most widely reported is the Morse Risk Assessment Tool; however, it has the lowest specificity and positive predictive value (PPV) of the 3 tools. Hendrich II has the best specificity and PPV overall. ${ }^{4}$

The review by Oliver et al evaluated the STRATIFY fall risk identification tool. Although STRATIFY is an easy tool to use, it had low specificity (51\%) and PPV (23\%). Only 4 of 8 studies included in the review met criteria for the meta-analysis and all involved geriatric rehabilitation patients.

The value of the study by Oliver et al is 2-fold. First, it shows that the STRATIFY tool is not operationally useful in geriatric rehabilitation inpatient settings; and second, that sensitivity, specificity, and PPV of the tool vary across settings and populations. It is important for nurses and other healthcare professionals to use fall risk assessment tools that have good sensitivity, specificity, and predictive values for specific clinical settings and populations. However, as noted by Oliver et al, fall risk assessment tools have limitations, so nurses should always conduct post-fall assessments and implement risk-minimisation plans for common risk factors identified in their patients.

Susan Kasseroler, RN, MSN, GNP-BC

Christus Hospital—St Elizabeth

Beaumont, Texas, USA
1. Tzeng HM, Yin CY. Nurses' solutions to prevent inpatient falls in hospital patient rooms. Nurs Econ 2008;26:179-87.

2. The Joint Commission. Defining the problem of falls. In Smith IJ, editor. Reducing the risk of falls in your health care organization. Oakbrook Terrace, IL; The Joint Commission on Accreditation, 2005: 13-27.

3. Centers for Medicare and Medicaid Services. Quality measures for reporting in fiscal year 2009 for 2010 update. 2008. www.cms.hhs.gov/apps/media/ press/factsheet.asp? Counter $=3044$ gintNumPerPage $=$ $10 \&$ checkDate $=\&$ checkKey $=\& s r c h T y p e=1$ \&numDay$\mathrm{s}=3500 \& \mathrm{srch} 0 \mathrm{pt}=0 \mathrm{qs} \mathrm{rchData}=$ \&keywordType $=$ All chkNewsType $=6$ gintPage $=$ \&showAll $=$ \&pYear $=$ \&yea$\mathrm{r}=$ gdesc $=$ falseqcboOrder $=$ date $($ accessed $25 \mathrm{Mar}$ 2008).

4. Currie L. Fall and injury prevention. In: Hughes RG editor. Patient safety and quality: an evidence-based handbook for nurses. AHRO Publication No 08-0043. Rockville, MD: Agency for Healthcare Research and Quality, 2008. 